\title{
A very rare association of hereditary breast cancer-pregnancy associated, with familial conjoined twin of rarest variety
}

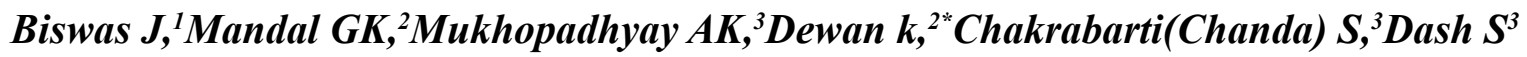 \\ ${ }^{1}$ Professor and Director, ${ }^{2}$ Department. of Pathology, Chittaranjan National Cancer Institute, West Bengal, India \\ ${ }^{3}$ Chittaranjan SevaSadancollege of Obstetrics and Gynaecology, West Bengal, India
}

\author{
*Corresponding Author: \\ Dr koushik dewan \\ Department. Of Pathology, Chittaranjan National Cancer \\ Institute, West Bengal, India \\ Email: dockoushik@gmail.com

\section{Citation} \\ Biswas J, Mandal GK, Mukhopadhyay AK, Dewan k, \\ Chakrabarti(Chanda) S, Dash S. A very rare association \\ of hereditary breast cancer-pregnancy associated, with \\ familial conjoined twin of rarest variety.. Nepal Journal \\ of Medical Sciences 2014;3(1):68-71.
}

\begin{abstract}
Pregnancy-associated breast cancer (PABC) is itselfa rare entity and even has very rare familial association.Here not only we report a case of PABC in a young lady but another incidental finding of rarest type of conjoined twin classified as dicephalus dibrachius dipus revealed during medical termination of pregnancy.Ultimately at the same time we managed to retrieve a familial association with both neoplastic and nonneoplasticconditions from her family pedigree.
\end{abstract}

Keywords:-Conjoined twin;familial association;Pregnancy-associated breast cancer

\section{Introduction:}

Breast cancer which is diagnosed during pregnancy, lactation and up to one year postpartum is called PregnancyAssociated Breast Cancer (PABC). One out of thousand pregnancies, with a median age 32 to 38 years and median gestational age 17 to 25 weeks is complicated by cancer. ${ }^{1,2}$ and breast cancer is the second most common diagnosed malignancy after cervical cancer. ${ }^{3}$ Here we report a case of PABC with a positive family history, probably a case of Hereditary Breast-ovarian cancer syndrome (HBOC) ${ }^{4}$ with multiple genetic aberrations ${ }^{5}$. The uniqueness lies not only with the PABC but also with the familial conjoined twinning which is extremely rare. In last decade this is the first reported case of PABC with familial association. Breast cancers in such cases are considered as highly aggressive and therefore, managed promptly. During management, medical termination was advised and the fetus was a conjoined twin classified as dicephalus dibrachius dipus. From history we figured out the Mendelian association with both neoplastic and non-neoplastic conditions, inherited from maternal and paternal family lines respectively, ultimately co-expressing in this patient.

\section{Case report:}

A 28 years old pregnant Indian lady of Christian community presented in our department with a complaint of increase in size of breast lump in left breast for last 4weeks. On physical examination a hard mass $(3 \times 2.5 \mathrm{~cm})$ was palpable in the upper outer quadrant of left breast. The patient was married one year back and she was pregnant for last 20 weeks. She has a family history of breast cancer of her mother, maternal aunt and grandmother, all of whom died of breast carcinoma. 6-7 years ago. She had a lump in her right breast which was removed and was confirmed as benign 3-4 years ago. She noticed a lump in her left breast for last three months which was increasing in size. Without any delay, considering this case to be a case of pregnancy associated breast cancer, patient was sent for ultrasonography and not for mammography. Ultrasonography revealed a heterogeneous mass with relatively high internal echogenicity without any 
axillary lymph node enlargement on that side. Without any further delay a USG guided fine needle aspiration (FNA) was done in the same sitting.On the same day FNA was reported as duct carcinoma of breast. An urgent tumourboard consisting of a surgeon, an oncologist, a radiotherapist, a pathologist,an anaesthesiologist, an obstetrician and a breast cancer specialist nurse was arranged.Accordingly next day a trucut biopsy was done under general anaesthesia and tissue sent for both histopathological examination and immunohistochemistry (IHC)for hormonal status. When we were waiting for biopsy repot, a thorough whole body screening programme was done specially of the ovaries, considering the entity of BRCA $1 \& 2$ syndrome. Biopsy report revealed that it was a case of invasive duct carcinoma grade III and IHC reports confirmed that it was ER POSITIVE, PR \& HER2 NEU positive breast carcinoma. A USG scan in the first trimester suggested twin fetus having discordant growth, however, the scan at 18 weeks was suggestive of a conjoined twin (although the type of conjoined twin was not specified). Prognosis was explained to the patient party in detail and as per their decision immediate medical termination was carried out under guidance of obstetrician. The termination was done by prostaglandin analogue induction and the fetus was expelled out through vaginal route. After the fetus was delivered, we found that the fetus itself is a rare entity of conjoined twin, having two heads but a single trunk two hands and two feet (dicephalus dibrachius dipus). Her relatives informed that similar incidence of conjoined twinning, had happened twice in her father's family line in two subsequent generations. Her grandmother was a parapagus twin who was successfully separated, the other conjoined twins were the two sons of her uncle who were thoracopagus twins. After that, the lady was managed for breast carcinoma along the lines of Conservative breast surgery with axillary clearance followed by adjuvant chemotherapy and hormonal therapy.Following which one cycle locoregional radiation will be given. Considering her marital status a decision of breast reconstruction surgery was also taken by the tumour board. Till date, two weeks after surgery patient is doing well both clinically and mentally.

\section{Discussion:}

PABC

itself is a highly aggressive tumour as because daily chances of metastasis for an untreated breast cancer in pregnancy is $0.057 \%{ }^{6}$ So early diagnosis, multidisciplinary treatment in proper time not only saves the life of victim but also is sometimes valuable for the baby. We faced difficulty in this case because of improper attention from patient side and her treating physician. The reason behind this is the normal increase in density of breast tissue during pregnancy. Here we used ultrasongraphy not only to avoid exposure of the baby by mammography but also to take a USG guided FNA from proper site in same sitting. On the very next day we performed trucut biopsy under general anaesthesia to avoid the risk to the baby due to anaesthetic drug and also to avoid anaphylactic reactions. After getting biopsy and immunohistochemistry considering the grade, age, family history and hormonal receptor status we planned for multidisciplinary treatment for this victim of mendelian association and so medical abortion was advised considering the report of conjoined fetus. The fetus that was expelled at 20 weeks of gestation turned out to be an extremely rare variety of conjoined twin. The incidence of dizygotic twin varies throughout the world whereas the incidence of monozygotic twinning is constant at 3.5 per 1000 births. The incidence of conjoined twins is approximately 1\% among monozygotic twins ${ }^{10}$, the estimated incidence varies from 1 in 30,000 to 1 in 100,000 among live births. Conjoined twinning occurs when the blastocyst divides beyond 12 days of fertilisation after the embryonic sac and rudimentary amniotic sac has been formed and is exclusively associated with monochorionic- monoamniotic placentation. Conjoined twins are classified according to most prominent site of union with "pagus" which in Greek terms mean "fixed".Thoracoomphalopagus twins are the commonest form of twins ${ }^{7}$ which are joined at the chest and abdominal region. After getting a written consent from family member autopsy was performed by standard technique adopted by Potter $^{9}$ and female genitalia was identified which correlated with the female preponderance among twins. At the same time we managed to retrieve a familial association with both neoplastic and nonneoplastic conditions from both the parental pedigree.

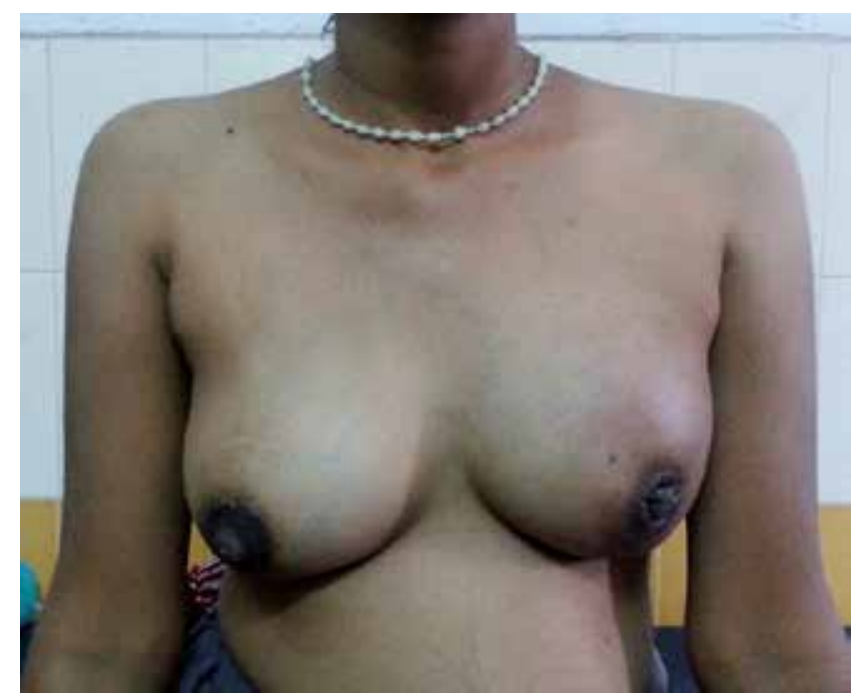

Figure 1: Pre-operatively left breast is seen to have malignant changes of nipple retraction, peau d'orange while the pregnancy associated changes are more obvious in the right breast 


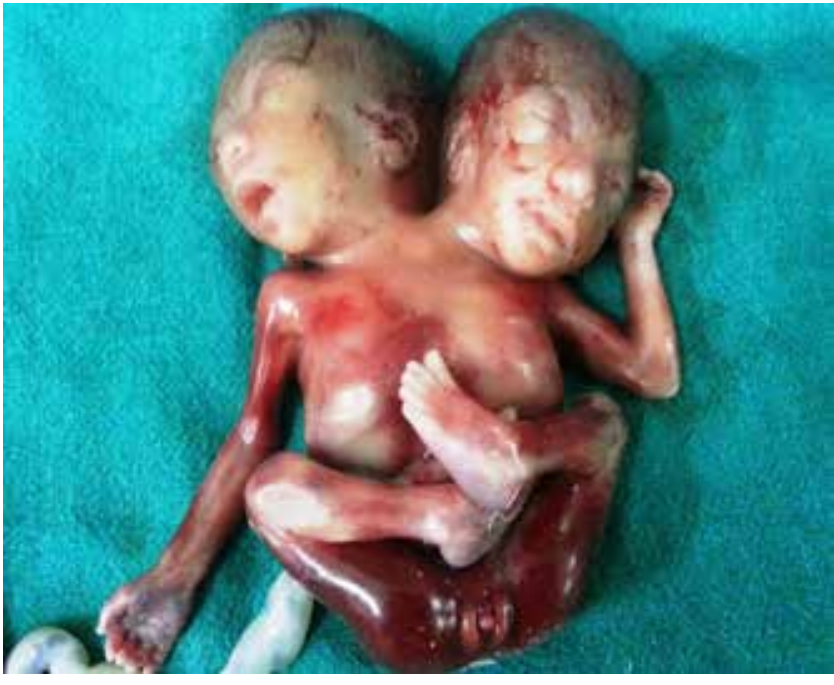

Figure 2:Conjoined female twin fetus expelled out vaginally.

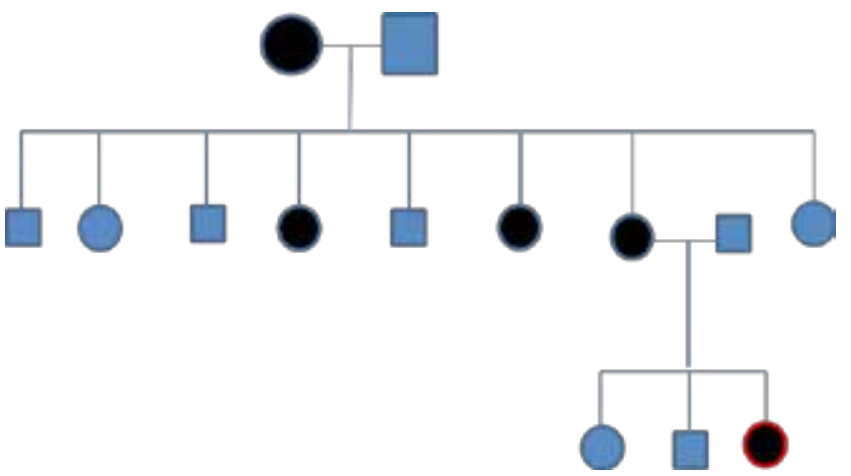

Figure 3A: Pedigree analysis of maternal family line.

Dark circles indicate breast carcinoma affected members.

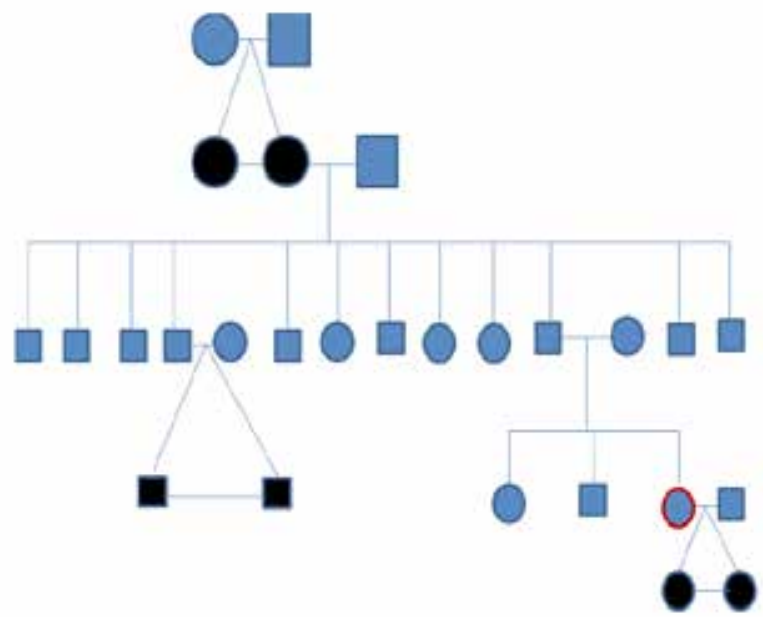

Figure3B: paternal family tree showing the familial conjoined twinning. The dark circles represent conjoined twins

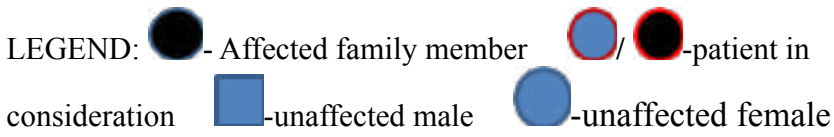

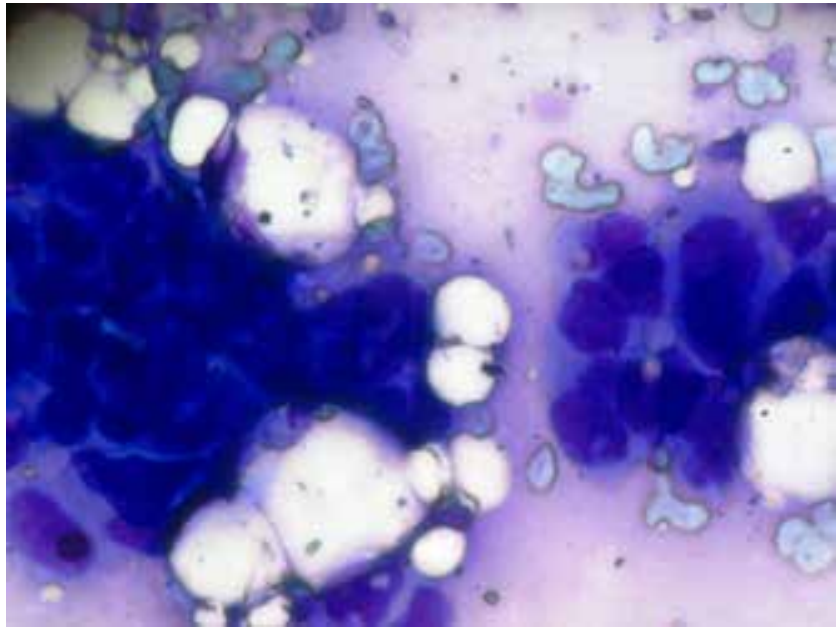

Figure 4:- (Giemsa 400X) FNA smear shows duct carcinoma cells intermingled with milk fat globules

\section{Conclusion:}

Though we could not find out all genetic aberrations in this case yet this rare familial neoplastic and non-neoplastic association gives the message that this type of association may exist and should be sought for and must be reported for future research. Our meticulous treatment approach in this particular case may help guidingmanagement of such future cases.

\section{References:}

[1] Keleher AJ, Theriault RL, Gwyn KM, et al. Multidisciplinary management of breast cancer concurrent with pregnancy. J Am CollSurg 2001;194:54-64.

http://dx.doi.org/10.1016/S1072-7515(01)01105-X

[2] Berry DL, Theriault RL, Holmes FA, et al. Management of breast cancer during pregnancy using astandardized protocol. J ClinOncol 1999; 17:855-61.

[3] Loibl S, Minckwitz G, Gwyn K, et al.Breast carcinoma in pregnancy international recommendations from an expert meeting.Cancer. 2006;106:237-46.

\section{http://dx.doi.org/10.1002/cncr.21610}

[4] Hereditary Breast Ovarian Cancer Syndrome (BRCA1 / BRCA2). Stanford University.Available at; http:// cancer.stanford.edu/information/geneticsAndCancer/ types/herbocs/.

[5] Morris JL, Gordon OK. Positive results : making the best decisions when you're at high risk for breast or ovarian cancer.Amherst, N.Y.: Prometheus 
Cose Report | Biswas J, et al. Bishwas J, et al. Hereditary pregnancy associated breast cancer and familial conjoined twin

Books, 2010.

[6] Nettleton J, Long J, Kuban D, et al.Breast cancer during pregnancy:quantifying the risk of treatmentdelay. ObstetGynecol 1996;87:414-8.

http://dx.doi.org/10.1016/0029-7844(95)00470-X

[7] Conjoined Twins Facts.University of Maryland Medical Center. Available at; http://www.umm.edu/ conjoined_twins/facts.htm.
[8] Kaufmann MH. The embryology of conjoined twins. Childs NervSyst 2004;20:508-25.

[9] Potter EL. Pathology of the Fetus and Infants. $1^{\text {st }}$ ed. New York:Mosby,1997.

[10] Edmonds LD, Layde PM. Conjoined twins in the United States 1970-1979.Teratology 1892;25:301-8.

http://dx.doi.org/10.1002/tera.1420250306 